\title{
Overall Rhetorical Structure of Students' English and Persian Argumentative Essays
}

\author{
Farzaneh Khodabandeh \\ Tehran Payame Noor University, Iran \\ Manoochehr Jafarigohar \\ Tehran Payame Noor University, Iran \\ Hassan Soleimani \\ Tehran Payame Noor University, Iran \\ Fatemeh Hemmati \\ Tehran Payame Noor University, Iran
}

\begin{abstract}
This study investigates commonalities and differences in overall rhetorical structure within the Iranian EFL subjects in their Persian and English pre- and post-argumentative essays and also it examines the effect of two different treatments, namely, models with implicit instruction, and models alone. After conducting TOFEL test, 76 subjects were selected. They were randomly divided into two groups, an experimental group which received no-instruction treatment, and a control group which was instructed implicitly. A pre-test and a post-test were administered before and after the treatment. The quantitative analysis of the post-argumentative essays revealed that the implicit group outperformed the no-instruction group. This study is significant for genre analysis and contrastive rhetoric research.
\end{abstract}

Index Terms - argumentative essay, contrastive rhetoric, deductive, inductive, both, off

\section{INTRODUCTION}

An ability to write appropriately and effectively is generally believed to be a formidable task for the English foreign language (EFL) students. Hyland (1992) believed this difficulty could be due to the fact that different levels of language knowledge such as rules of syntax, spelling, and cohesion are relevant to the writing process. Of all these, the most crucial challenge appeared to be learning how to organize and develop ideas in an academically persuasive manner; that is, to organize ideas into logical and cohesive arguments that will convince the reader (Hyland, 1999).

According to Kaplan (2005), even advanced students who have a good command of the syntactic structure and lexicon of English may still write papers that are considered ineffective and inadequate by native instructors.

To mitigate this problem, different researchers have conducted various corpus-based analyses and determined rhetorical organizations of different genres in order to find ways to facilitate writing by providing models of different communicative activities (Bhatia, 1993; Master, 1997).

As a result, the notion of genre and genre-based pedagogy in English language teaching, especially in the teaching and learning of English for specific purposes (ESP) have been emphasized (Hyland, 2002; Paltridge, 2001). Genrebased instruction involves of how to begin and end a text, what to put in the middle and of how to organize information (Hammond, 1987).

Basically, genre-based instruction is teaching language based on the results of genre analysis. Genre analysis studies the structural organization of texts by identifying the moves and strategies (Bhatia, 1997) and it examines how language is used within a particular setting and most often studies the production of moves (Swales, 1990).

Furthermore, genre theorists (Martin \& Rothery, 1980) argue that pupils will benefit from explicit or implicit teaching of various genres in the classrooms. As a result, composition practitioners might have seen increased emphasis being placed on the notion of genre and genre-based pedagogy in English language teaching and on the various types of academic writings (Hyland, 2002; Paltridge, 2001).

Argumentative writing as a mode of academic writing constitutes an important part of second-language learners' academic experience at the college level. It is a fundamental writing style across various English for Academic Purposes (EAP) and ESP writing tasks. It is considered as an important skill during the school years and beyond because it can empower individuals at work and in society (Nippold, 2000).

This study has chosen argumentative genre to investigate similarities and/or differences in the way Iranian students structure the overall rhetorical structure of their essay before and after instruction, it also examines the effect of implicit and no-formal genre-based instruction. The investigation was intended to address the following research question: 
Are there any significant differences in overall rhetorical structure, regarding the placement of the thesis statement (deductive, inductive, off, both) within the experimental and the control groups in their Persian and English pre- and post-argumentative essays?

\section{The Overall Rhetorical Structure of English Argumentative Essays}

The thesis statement provides the stance, the belief, or the point of view of the writer; or it states the purpose of the essay and conveys the central or main idea of the text (Yan \& Cahill, 2008).

Regarding the placement of the thesis statement, this study follows the approach introduced by Kubota (1998). There are four kinds of placing the claim. These four types are deductive, inductive, both, and off.

The first type, deductive, characterizes a paper in which a clear point of view is stated right in the beginning of paper followed by specific reasons and evidence supporting the position. In inductive kind, a writer's claim is presented at the end of the paper, and supporting evidence is stated in the beginning. The third type is called both which presents and discusses both points of view on a controversial topic in the beginning of the paper, and the writer's position is delayed until the end. Both papers differ from inductive papers in that the former devote a great deal of attention to presenting both sides of the controversial topic, with little space left for supporting the writer's own point of view, although the view is presented at the end of the paper (Kubota, 1998).

The fourth type is off-task. Papers within this category fail to address the writing task as required that is either they fail to provide a clear position or the position is a neutral one (i.e., presenting the advantages and disadvantages of a controversial issue without taking a stance).

\section{Empirical Studies on Contrastive Rhetoric}

Since the emergence of contrastive rhetoric, there has been great interest in examining English rhetorical patterns. Kaplan (1966) analyzed the organization of paragraphs in ESL student essays with focus on linearity and circularity. He found that the rhetorical pattern of English writing tend to be distinctively linear in the sense that it first states the topic of the essay and then develops the topic with relevant details through describing, defining, comparing, or illustrating.

Moradian (1999) examined the rhetorical construction of Persian and English newspaper editorials regarding the rhetorical writing styles of deduction, induction, and quasi-induction. They revealed that while Persian editorial writers used the quasi-inductive style, English editorial writers preferred the deductive style.

Hirose (2003) analyzed how 15 Japanese EFL students organized their Japanese and English argumentative essays. It was found that the organizational patterns of Japanese and English argumentative essays were similar, specifically, using deductive organization. Anyhow, the Japanese essays exhibited more variations in organizational patterns and had more uses of general or neutral information, which had no direct relevance to the argument.

Uysal (2008) examined rhetorical patterns in Turkish and English essays. Following Kubota (1998), the location of main ideas was coded as one of the following four: initial, middle, final, and collection. It was found that the participants tended to organize their Turkish essays in a way similar to the English ones, that is, the thesis statements were presented first, followed by explanation and evidence for the argument. These participants were also found to be reluctant to use topic sentences.

Khiabani and Pourghassemian's (2009) study aimed at investigating the differences in organizational patterns and the quality of L1/L2 argumentative writings of Iranian EFL students. The results indicated no significant difference between the organizational patterns of L1 and L2 writings despite the better quality of L1 writings which could have been due to the transfer of some rhetorical patterns from L1 to L2.

Rashidi and Dastkhezr (2009) compared Persian and English organizational patterns in the argumentative writing of Iranian EFL student writers. The study made within-subject comparisons of L1 and L2 compositions in terms of organizational patterns, organization scores, and overall quality. The results revealed that (a) a majority of students employed deductive type organizational patterns in both L1 and L2.

This dissertation research will contribute to the field of contrastive rhetoric by comparing English and Persian argumentative writing patterns as well as examining the effect of two instructional techniques (models with implicit instruction and models with no formal instruction). Hence, the present study could be considered as a contribution to this line of research.

\section{RESEARCH DESIGN}

The quasi-experimental design of the present research investigated the effectiveness of using an implicit and noinstruction genre-based approach to teaching the learners the placement of the thesis statement (deductive, inductive, both, off). The control subjects participated two instructional sessions; they were given four model essays and they read, discussed them in class, and responded orally to sets of questions provided by the instructor. The experimental group received no-instruction treatment; they were just given the model texts to read by themselves. At the end of the treatment, the subjects of the two groups participated in the post-test. All the procedures across the conditions were similar for the pre- and post-sessions

\section{A. Subjects}


Totally 90 EFL freshmen participated in the study. In order to have a homogenous sample, they were pre-tested through a TOEFL test. The selected subjects (76) were those with intermediate level of language proficiency.

All subjects were native speakers of Persian and had studied English for approximately six years at school. According to the results of the questionnaires of the study, the subjects had no previous argumentative writing experience in either English or in Persian and they were not familiar with the placement of the thesis statement (deductive, inductive, both, off).

\section{B. Administering the Pre-and Post-essay Writing}

Before the treatment, the subjects of the two groups wrote two argumentative essays (one in English and another one in Persian) without any prior instruction an in-class timed argumentative essay (referred to as the pre-test) in which they supported their stand on the issue (see Appendix A). Given that the students were required to compose two essays, in order to avoid collecting unreliable data, writing prompts for two different topics were designed so that students would not respond to the same topic twice. At the end of the treatment, the two groups were asked to write English and Persian essays on the different topics to test whether the subjects had acquired the ability to use proper rhetorical organization and how their writing products had changed from their pre-test.

\section{Model Texts}

The two groups were given the same model texts. Four sets of argumentative texts were selected from the IELTS book (Warshawsky, 2006). To fit the research purpose, the four texts had to have claims, data and similar lengths.

\section{Treatment}

The researcher exposed the subjects of the control group to two models of the argumentative genre. These were designed for the subjects to read and understand. In the implicit treatment the placement of the thesis statement (deductive, inductive, both, off) was not directly taught. In two sessions, the model texts were given to the subjects. They read the model essays and analyzed the introduction section, the body section; and the conclusion. The researcher provided learners with practice to ask questions. The experimental group received no formal instruction in English rhetorical patterns; instead, they engaged in reading argumentative essays by themselves.

\section{ANALYSIS OF L1/L2 ORGANIZATIONS}

The English and Persian pre- and post-argumentative essays were analyzed in terms of the placement of the thesis statement (deductive, inductive, both, off). Two raters who were experienced EFL professionals scored the essays. Because of the possible subjectivity associated with the rater scores, the consistency in assigned scores (scorer reliability) within and between raters were examined.

The computed Pearson correlation coefficient for the pre-test of English regarding the placement of the thesis statement, namely deductive, inductive, off and both were $.93, .92, .89, .95$ respectively and for the post-test of English regarding the use of thesis statement, deductive, inductive, off and both were $.98, .94, .91, .87$.

The computed Pearson correlation coefficient for the pre-test of Persian placement of the thesis statement, namely deductive, inductive, off and both were $.91, .93, .94, .95$ respectively and for the post-test of Persian regarding the use of thesis statement, deductive, inductive, off and both were $.91, .95, .91, .89$. The results indicate that there were a high positive relationship between the scores rated by rater 1 and rater 2 in the pre- and post- argumentative essays.

\section{Results}

The data used for the analysis were 304 English and Persian essays produced by the subjects of the two groups at the end of the treatment. A chi-square was employed for finding the significance of the differences between the two groups in terms of the placement of the thesis statement (deductive, inductive, both, off) in both English and Persian pre- and post-argumentative essays. The results are presented in Table 1. 
TABLE 1

OVERALL GROUP CROSS TABULATION

\begin{tabular}{|c|c|c|c|c|}
\hline & & \multicolumn{2}{|l|}{ GROUP } & \multirow[t]{2}{*}{ Total } \\
\hline & & Experimental & control & \\
\hline \multirow[t]{2}{*}{ Both post test English } & $\mathrm{N}$ & 1 & 3 & 4 \\
\hline & $\%$ & $25.0 \%$ & $75.0 \%$ & $100.0 \%$ \\
\hline \multirow[t]{2}{*}{ Both pre test English } & $\mathrm{N}$ & 3 & 1 & 4 \\
\hline & $\%$ & $75.0 \%$ & $25.0 \%$ & $100.0 \%$ \\
\hline \multirow{2}{*}{ Deductive post test English } & $\mathrm{N}$ & 6 & 26 & 32 \\
\hline & $\%$ & $18.8 \%$ & $81.3 \%$ & $100.0 \%$ \\
\hline \multirow[t]{2}{*}{ Deductive post test Persian } & $\mathrm{N}$ & 8 & 21 & 29 \\
\hline & $\%$ & $27.6 \%$ & $72.4 \%$ & $100.0 \%$ \\
\hline \multirow[t]{2}{*}{ Deductive pre test English } & $\mathrm{N}$ & 8 & 14 & 22 \\
\hline & $\%$ & $36.4 \%$ & $63.6 \%$ & $100.0 \%$ \\
\hline \multirow{2}{*}{ Deductive pre test Persian } & $\mathrm{N}$ & 10 & 7 & 17 \\
\hline & $\%$ & $58.8 \%$ & $41.2 \%$ & $100.0 \%$ \\
\hline \multirow[t]{2}{*}{ Inductive post test English } & $\mathrm{N}$ & 12 & 8 & 20 \\
\hline & $\%$ & $60.0 \%$ & $40.0 \%$ & $100.0 \%$ \\
\hline \multirow[t]{2}{*}{ Inductive post test Persian } & $\mathrm{N}$ & 12 & 12 & 24 \\
\hline & $\%$ & $50.0 \%$ & $50.0 \%$ & $100.0 \%$ \\
\hline \multirow[t]{2}{*}{ Inductive pre test English } & $\mathrm{N}$ & 8 & 4 & 12 \\
\hline & $\%$ & $66.7 \%$ & $33.3 \%$ & $100.0 \%$ \\
\hline \multirow[t]{2}{*}{ Inductive pre test Persian } & $\mathrm{N}$ & 8 & 12 & 20 \\
\hline & $\%$ & $40.0 \%$ & $60.0 \%$ & $100.0 \%$ \\
\hline \multirow[t]{2}{*}{ Off post test English } & $\mathrm{N}$ & 19 & 1 & 20 \\
\hline & $\%$ & $95.0 \%$ & $5.0 \%$ & $100.0 \%$ \\
\hline \multirow[t]{2}{*}{ Off post test Persian } & $\mathrm{N}$ & 18 & 5 & 23 \\
\hline & $\%$ & $78.3 \%$ & $21.7 \%$ & $100.0 \%$ \\
\hline \multirow[t]{2}{*}{ Off pre test English } & $\mathrm{N}$ & 19 & 19 & 38 \\
\hline & $\%$ & $50.0 \%$ & $50.0 \%$ & $100.0 \%$ \\
\hline \multirow{2}{*}{ Off pre test Persian } & $\mathrm{N}$ & 20 & 19 & 39 \\
\hline & $\%$ & $51.3 \%$ & $48.7 \%$ & $100.0 \%$ \\
\hline \multirow[t]{2}{*}{ Total } & $\mathrm{N}$ & 152 & 152 & 304 \\
\hline & $\%$ & $50.0 \%$ & $50.0 \%$ & $100.0 \%$ \\
\hline
\end{tabular}

According to Table 1 the frequency of off type organizational pattern employed per English pre-argumentative essays across the control and the experimental groups was 50.0\%, 50.0\% and the frequency of Off type employed per Persian pre-argumentative essays across the control and the experimental groups was 48.7\%, 51.3\% respectively.

An example of off type written by one of the subjects of the control group is presented here. In the excerpt, the writer does not provide a clear position.

Example 1: Off paper. Topic: marriage

There are two kinds of marriage in Iran, modern, traditional. Most of the people do both of them. For example, first several hours in traditional ceremony and after that people prefer to have modern wedding. In modern marriage boys and girls make friendship before get married. Usually they get family through friends or net or pub places. In this kind of marriage couples get tired of each other so soon because they can not deal with their expectations. They think about a romantic life with their partner before marriage but after that they face problems of life. But in traditional marriage kids get familiar before marriage. They consult any items that think maybe have negative affect in their next life; and try to solve them, and satisfaction of parent is so important too and have positive affect on the life of child.

As Table 1 shows, the frequency of deductive type organizational pattern employed per English post-argumentative essays across the control and the experimental groups was $81.3 \%, 18.8 \%$ and the frequency of deductive type employed per Persian post-argumentative essays across the control and the experimental groups was $72.4 \%, 27.6 \%$ respectively. The Table shows that a small number of papers used inductive pattern. Almost no both type pattern was used in the English and Persian essays.

Example 2: Deductive paper. Topic: marriage

Today marriage is a very hot topic among people, specially among young ones. Some are agree with modern and some are agree with traditional one. I myself agree with modern one because of some reasons such as communication, and compatibility.

One of the important point in marriage is communication. If the couples don't know each other as well it cause some misunderstanding and their marriage can break up easily, because each partner have his own expectation and other partner cannot guess it unless they have a good and healthy communication before their marriage.

Compatibility can be another major point for marriage. Marriage is not just about physical compatibility, the couple should have mental compatibility as well to have a successful marriage and it never create in traditional marriage.

As a conclusion if parents have forced their daughter or son or let them married without understanding each other without paying attention their interests, it too many times ends up in divorce. 
TABLE 2.

\begin{tabular}{llll} 
CHI-SQUARE TESTS OF PLACEMENT OF THE THESIS STATEMENT IN THE ENGLISH AND PERSIAN ESSAYS \\
\hline & Value & $d f$ & Asymp. Sig. (2-sided) \\
\hline $\begin{array}{l}\text { Pearson Chi-Square } \\
N \text { of Valid Cases }\end{array}$ & 49.000 & 13 & .000 \\
\hline
\end{tabular}

The result of chi-square test $\left(x^{2}=49, d f=13, p=.000<0.05\right)$ indicates that there are significant differences between the two groups in terms of the placement of the thesis statement in both English and Persian pre- and post-argumentative essays.

\section{CONCLUSION}

The results revealed that a majority of students of the two groups employed off type organizational patterns in both English and Persian pre-argumentative essays; that is, the subjects of both groups failed to provide a clear position. In contrastive rhetoric research, it has been assumed that EFL students organize their EFL texts in the same way they do their Ll writing influenced by Ll conventions and that this approach negatively affects the quality of their EFL essays. The results of this study, however, showed that almost all students wrote in a similar way in the two languages. This finding is not in line with those of Hirose (2003), who found that the organizational patterns of Japanese and English argumentative essays were similar in using deductive organization where the main idea was presented initially in paper.

The results are also in line with findings reported by other Iranian researchers of contrastive rhetoric (Khiabani \& Pourghassemi, 2009; Rashidi \& Dastkhezr, 2009), who showed that the participants of their study used similar organizational patterns in both their L1 and L2 writings as there did not exist any significant difference between the location of main idea and macro-level structures they used on the two writings.

Similar to Hirose (2003), Uysal (2008) reported that the Turkish participants in her study organized Turkish and English papers similarly by presenting the thesis statements first followed by explanation and evidence for the argument, which is not consistent with the present study.

Regarding the participants' English and Persian post-argumentative essays, the control group used the deductive type in their English and Persian post-argumentative essays while the experimental group didn't. In this study, most control subjects put their positions in the initial section and used the deductive pattern in English and Persian postargumentative essays which can be concluded that exposing the participants to the model texts can be surmised to have been made across languages. Results indicated that the implicit instructed students used significantly more deductive type pattern in their essays and followed the model organization more closely than those students who only received models (the non- instructed students).

It should be noted that, in the present study, a relatively a small number of papers employed inductive organization, and it seems that the both papers were not used in the Persian pre- and post-argumentative papers. Kobayashi and Rinnert (2008) called this type of discourse organization "exposition" which comprised a discussion of a topic without taking a side but analyzing the advantages and disadvantages of each. They also found that students tended to use exposition when they wrote the Japanese essays, which does not confirm the finding of the present study.

The results of the study justify the claim that the implicit teaching of genre develops students' writing abilities and genre awareness. By being taught implicitly, students can gain control over genres and as there is a lack of Persian rhetorical instruction in schools, writing instruction in a second language may compensate for this gap; thus, transfer from $\mathrm{L} 2$ to $\mathrm{Ll}$ would be a desired positive fact.

One such instructional strategy that was particularly effective was teacher modeling. Teachers could use modeling to provide students with the processes necessary for learning, attention, retention, and reproduction (Bandura, 1977).

Regarding contrastive rhetoric research, the initial purpose of this research was to offer pedagogical suggestions for teaching EFL writing. The findings of this study offered some implications about the type of organizational patterns and rhetorical elements which would help students improve their argumentative essay writing. In this regard, Gao (2007) argued that it is important for non-native learners of English to make an effort to adopt the writing style that native speakers use, especially on the sociolinguistic level.

Contrasting English and Persian argumentative essays has a lot to offer to teachers and students. Firstly, it explains patterns of essay writing in both English and Persian languages. Purves (1988) emphasizes that the understanding of the rhetorical deviations among languages "would bridge the gap between cultural encoding and decoding" (p. 19). He suggests that instructors should be aware that, in essence, "differences among rhetorical patterns do not represent differences in cognitive ability, but differences in cognitive style” (p. 19). Contrasting English and Persian essay writing helps teachers make students aware of different writing styles and different audience expectations when writing in other languages.

Several questions remain for future research. First, the small sample size of the subjects may limit the generalizability of the results; thus, the findings should be confirmed with a larger sample of participants. This study, featuring withinsubject comparison, only compared EFL intermediate learners. Future investigations are expected to focus on comparison of L1 and L2 writing performance of students at various levels such as those with higher or lower L2 proficiency levels. 
With regard to the two different kinds of treatments used in the research, the study would perhaps be enhanced by rating investigation of combing explicit, implicit and no-formal instruction on argumentative essay with an attempt to integrate reading and writing skills.

\section{APPENDIX A WRITING PROMPT FOR THE ENGLISH PRE-ARGUMENTATIVE TASK}

Name:

Class number:

Student number:

Date:

Time 45 minutes

"There are two ways of marriage in Iran: traditional and modern one. Some argue that parents should choose their son's or daughter's spouse (in a traditional way); however, there are strong arguments against it. Use specific reasons and examples to support your position."

On the afternoon of the pre-test day, all the two groups were asked to write a Persian essay. The prompt given to the students in Persian was as follows:

"Some argue that the university entrance exam should be omitted; however, there are strong arguments against it. Use specific reasons and examples to support your position. "

\section{APPENDIX B WRITING PROMPT FOR THE ENGLISH POST-ARGUMENTATIVE TASK}

"Some argue that the students should have a part time job; however, there are strong arguments against it. Use specific reasons and examples to support your position."

On the afternoon of the pre-test day, all the two groups were asked to write a Persian essay. The prompt given to the students in Persian was as follows:

The prompt given to the students in Persian was as follows:

"Some argue that News should be censored in Iran; however, there are strong arguments against it. Use specific reasons and examples to support your position."

\section{REFERENCES}

[1] Bandura, A. (1977). Social learning theory. New York: General Learning Press.

[2] Bhatia, V. (1993). Analyzing genre: Language use in professional settings. London: Longman.

[3] Bhatia, V. (1997). Genre-mixing in academic introductions. English for Specific Purposes, 16(3), 181-195.

[4] Gao, J. (2007). Teaching writing in Chinese universities: Finding an eclectic approach. Asian EFL Journal, 20(2), $285-297$.

[5] Hammond, J. (1987). An overview of the genre-based approach to the teaching of writing in Australia. Australian Review of Applied Linguistics, 10, 163-181.

[6] Hirose, K. (2003). Comparing LI and L2 organizational patterns in the argumentative writing of Japanese EFL students. Journal of Second Language Writing, 12, 181-209.

[7] Hyland, K. (1992). Genre analysis: Just another fad? English Teaching Forum, 30 (2), 14-17.

[8] Hyland, K. (1999). Academic attribution: Citation and the construction of disciplinary knowledge. Applied Linguistics, 20, 341367.

[9] Hyland, K. (2002). Teaching and researching writing. Harlow: Longman.

[10] Kaplan, R. B. (1966). Cultural thought patterns in intercultural education. Language Learning, 16, 1-20.

[11] Kaplan, R. B. (2005). Contrastive rhetoric. In E. Hinkel (Ed.), Handbook of research in second language teaching and learning (pp. 375-392). Mahwah, N.J.: Lawrence Erlbaum Associates.

[12] Khiabani, N. \& Pourghassemi, H. (2009). Transfer of L1 organizational patterns in argumentative writing of Iranian EFL students: Implications for contrastive rhetoric, Iranian Journal of TEFLL, 1(4), 23-38.

[13] Kobayashi, H., \& Rinnert, C. (2002). High school student perceptions of first language literacy instruction: Implications for second language writing. Journal of Second Language Writing, 11, 91-116.

[14] Kubota, R. (1998). An investigation of L1-L2 transfer in writing among Japanese university students: Implications for contrastive rhetoric. Journal of Second Language Writing, 7, 69-100.

[15] Martin, J. R., \& Rothery, J. (1980). Writing project: Report no. 1. Working papers in linguistics. Sydney: University of Sydney.

[16] Master, P. (1997). The English article system: Acquisition, function, and pedagogy. System 2(2), 215-232.

[17] Moradian, M. R. (1999). A contrastive rhetoric study: the use of deductive, inductive, and quasi-inductive writing styles in Persian and English newspaper editorials. Unpublished Master's thesis. University of Tehran, Iran.

[18] Nippold, M. A. (2000). Language development during the adolescent years: Aspects of pragmatics, syntax, and semantics. Topics in Language Disorders, 20 (2), 15-28.

[19] Paltridge, B. (2001). Genre and the language learning classroom. Ann Arbor: University of Michigan Press.

[20] Purves, A. (1988). Writing across languages and cultures: Issues in contrastive rhetoric. Newbury Part: SAGE Publications.

[21] Rashidi, N., \& Dastkhezr, Z. (2009). A comparison of English and Persian organizational patterns in the argumentative writing of Iranian EFL students. JOLIE, 2(1), 131- 152.

[22] Swales, J. (1990). Genre analysis: English in academic and research settings. Cambridge: Cambridge University Press.

[23] Uysal, H. (2008). Tracing the culture behind writing: Rhetorical patterns and bidirectional transfer in LI and L2 essays of Turkish writers in relation to educational context. Journal of Second Language Writing, 17, 183-207.

[24] Warshawsky, D. (2006). Cambridge IELTS book 1- 10, Examination papers from university of Cambridge ESOL examination: English for speakers of other languages. Cambridge: Cambridge University Press. 
[25] Yang, L., \& Cahill, D. (2008). The rhetorical organization of Chinese and American students' expository essays: A contrastive rhetoric study. International Journal of English Studies, 8, 113-132.

Farzaneh Khodabadeh is an instructor at Mobarakeh Payame Noor University and a Ph.D student teaching reading, writing, grammar, translation, and conversation with research interests in contrastive rhetoric, genre analysis, pragmatics, and discourse analysis.

Manoochehr Jafarigohar: Ph.D. in TEFL, MA in TEFL, BA in English translation; author of thirteen academic textbooks; presentation in more than 20 international conferences; published papers in various journals; 25 year experience of teaching English; 20 years of teaching and research in distance education; advisor and reader to over 100 post-graduate theses and dissertations

Hassan Soleimani is an assistant professor at the University of Payame Noor, Tehran, Iran, where he teaches computer-assisted language learning and EFL curriculum development for Ph.D. candidates, and research methods and language teaching methodology to graduate and undergradute students. He has written some books, including An Introduction to Non-parametric Statistics for Applied Linguistics Research (2009), and articles in national and international journals. He also serves as the editorial board member of some journals. His areas of interest include research methodology and statistics, curriculum design, and SLA issues.

Fatemeh Hemmati, PhD, Assistant Professor, University of Payame Noor Iran. 